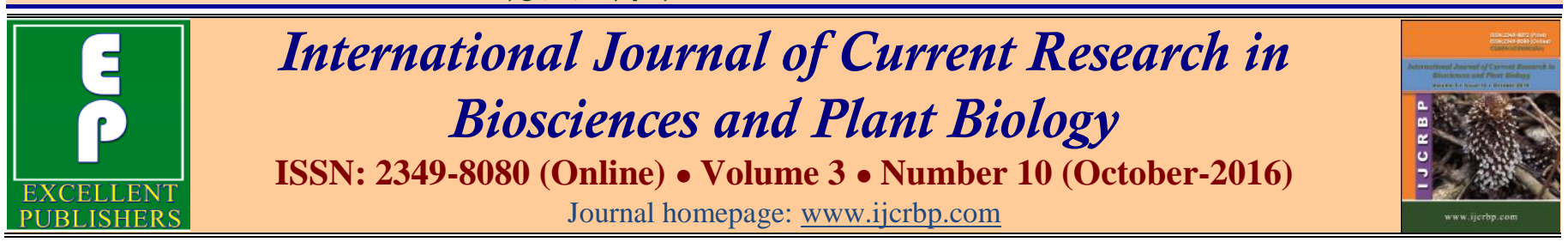

\title{
Determination of Acquaintance between Biofilm and Extended Spectrum of $\beta$-Lactamases Producers from Diarrheal Stool Isolates of Escherichia coli
}

\author{
D. Jegadeeshkumar' ${ }^{1}$ K. S. Rajen ${ }^{2}$, P. Nirmala ${ }^{3}$, L. R. Gopinath ${ }^{3}$ and B. Prakash ${ }^{*}$
}

${ }^{1}$ Reseach Scholar, Manonmaniam Sundaranar University, Tirunelveli-627 012, Tamil Nadu, India

${ }^{2}$ Department of Microbiology, Mannai Rajagopalasamy Government Arts College, Mannargudi- 614 oo1, Tamil Nadu, India

3Department of Biotechnology, Vivekanandha College of Arts \& Science for Women, Tiruchengode- 637 205, Tamil Nadu, India

*Corresponding author.

\begin{abstract}
A b stract
The study was to assess the prevalence of extended spectrum beta-lactamases (ESBL) positive isolates from diarrheal stool samples in Namakkal District, Tamil Nadu (India). Totally 68 isolates were recovered from 125 samples and the isolates were identified as Escherichia coli by biochemical test and selective media. All isolates were subjected to determination of biofilm formation with tube method, among them $36(53 \%)$ isolates were biofilm producers. The ESBL production was detected using a double disc synergy test and the presence of ESBL genes was evaluated by the Multiplex PCR method. In this study, 32.3\% of isolates has been at least one type of ESBL genes, among them CTXm was most predominate gene. This result was acquainted with biofilm producers, and it was found that biofilm producing isolates mostly harbored the ESBL genes in comparison with non-biofilm producers.
\end{abstract}

\section{Introduction}

Diarrheal diseases are the leading cause of morbidity and mortality in developing countries. This accounts for nearly 1.3 million deaths in every year and mainly affected in less than 5 years of age. Over half of the deaths occur in developing countries such as India, Nigeria, Afghanistan, Pakistan and Ethiopia (http://www.unicef.org/).Several pathogens such as bacteria, viruses and parasites are the causes of diarrhea in human. Among them, Escherichia coli is the most important etiologic agents for diarrheal diseases (Ferro et al., 2012). Many reports have demonstrated that association of enteroaggregative $E$. coli with diarrhea in children in developing countries. Some authors report persistent diarrhea mainly caused by enteroaggregative E. coli and which produced biofilm formation. Biofilm producing isolates are very difficult to treat because isolates are express several virulence factors and an increased resistance against phagocytosis (Costerton et al., 1999; Murugan et al., 2011).

Now a day Enterobacteriaceae is highly resistant to extended spectrum beta-lactamase (ESBL) has been reported all over the world, especially in Asian countries. Most of the biofilm producing isolates were ESBL producers and mainly harbored the blaCTX-M (Pourakbari et al., 2012; Singhai et al., 2014). ESBLproducing organisms frequently show cross-resistance to many other classes of antibiotics; including amino glycosides and fluoroquinolones, thus treatment of these infections are often a therapeutic challenge (Ponnusamy, 2013). According to earlier studies, very few reports only 
spotted to biofilm produced isolates had ESBL genes. High prevalence of ESBL producing isolates creates a great need to identify the presence of these ESBL enzymes in clinical isolates accurately. The aim of the present study was determined the prevalence and acquaintance of ESBL genes in biofilm producing diarrheal isolates of $E$. coli.

\section{Materials and methods}

A total of 125 samples were collected from infants and other age groups between zero to 60 years suffering from diarrhoea (more than 3 loose stools per day for 2-3 days) admitted to a private hospital in around Namakkal area. These patients presented varying kinds of symptoms ranging from nausea, vomiting and had not taken any antimicrobial agents during the week of preceding sampling. Patients with concomitant infections were excluded from the study.

Sterile plastic container was used for the sample collection and the collected stool samples were transported at room temperature $\left(25-30^{\circ} \mathrm{C}\right)$ within $1 \mathrm{hr}$ to the laboratory for microbiological analysis. All stool samples were inoculated into MacConkey and EMB agar. After the aerobic incubation period at $37^{\circ} \mathrm{C}$ for 24 hrs, the plates were then observed for bacterial growth. Selected colonies were sub cultured into nutrient agar. Further analysis of isolates was by standard biochemical method as described by Cowan and Steel (1974).

\section{Biofilm formation}

The determination of the biofilm production was done on the basis of the adherence of the biofilm to borosilicate test tube as was done by the procedure of Christensen et al. (1982). The suspicion isolates was inoculated with test tube containing trypticase soy broth and incubated for $24 \mathrm{hrs}$ at $37^{\circ} \mathrm{C}$. The tubes were decanted and washed with PBS ( $\mathrm{pH}$ 7.2). Air dried the tubes and stained with $0.1 \%$ of crystal violet. Excess stain was removed and tubes were washed with deionized water, than tubes were dried and observed the result. The positive result was indicated as the presence of a layer of the stained material which adhered to the inner wall of the tubes. The exclusive observation of a stained ring at the liquid air interface was considered as negative.

\section{Screening of ESBL producing isolates}

The ESBL production was tested by the Modified Double Disc Synergy Test (MDDST) by using a disc of amoxicillin-clavulanate $(20 / 10 \mu \mathrm{g})$ along with four cephalosporins, cefotaxime, ceftriaxone, cefpodoxime and cefepime. A disc which contained amoxicillinclavulanate $(20 / 10 \mu \mathrm{g})$ was placed in the centre of the plate. The other discs were placed around the amoxicillin-clavulanate disc (Kaur et al., 2013).When zone was enlarged more than $5 \mathrm{~mm}$ around the disk containing clavulanic acid the isolate were considered as ESBL positive.

\section{PCR amplification for detection of beta lactamase genes}

All isolates were screened for the resistance genes SHV, TEM, CTX-M, and OXA by a multiplex PCR assay using Hong Fang et al. (2008) procedure (Table 1). Plasmid DNA extraction was performed by using a Helini DNA isolation kit (India, Chennai). PCR amplification reactions were performed in a volume of $25 \mu$ l containing $12.5 \mu \mathrm{l}$ of $2 x$ Promega PCR Master Mix (USA), $0.2 \mu \mathrm{M}$ concentrations of each primer, and $2 \mu \mathrm{l}$ of DNA template. The cycling parameters were as follows: an initial denaturation at $95^{\circ} \mathrm{C}$ for $15 \mathrm{~min}$; followed by 30 cycles of $94^{\circ} \mathrm{C}$ for $30 \mathrm{~s}, 62^{\circ} \mathrm{C}$ for $90 \mathrm{~s}$, and $72^{\circ} \mathrm{C}$ for $60 \mathrm{~s}$; and with a final extension at $72^{\circ} \mathrm{C}$ for $10 \mathrm{~min}$. The amplified PCR products were subjected to electrophoresis at a $1.5 \%$ agarose gel in 1XTBE buffer. A 100bp ladder molecular weight marker (Helini, India) was used to measure the molecular weights of amplified products.

Table 1. Primer sequence for ESBL genes.

\begin{tabular}{lll}
\hline Gene & Primer sequence & Size (bp) \\
\hline SHV & CTT TAT CGG CCC TCA CTC AA & 237 \\
& AGG TGC TCA TCA TGG GAA AG & \\
TEM & CGC CGC ATA CAC TAT TCT CAG AAT GA & 445 \\
& ACG CTC ACC GGC TCC AGA TTT AT & \\
CTXm & ATG TGC AGY ACC AGT AAR GTK ATG GC & 593 \\
& TGG GTR AAR TAR GTS ACC AGA AYC AGC GG & \\
OXA & ACA CAA TAC ATA TCA ACT TCG C & 813 \\
& AGT GTG TTT AGA ATG GTG ATC & \\
\hline
\end{tabular}

D. Jegadeeshkumar et al. (2016) / Determination of Acquaintance between Biofilm and Extended Spectrum $\beta$-Lactamases Producers from Diarrheal Stool Isolates of Escherichia coli 


\section{Results and discussion}

Out of 125 diarrheal stools analyzed, 68 samples containing the blood yielded biochemically confirmed $E$. coli isolates by conventional culture technique (Fig. 1). PCR performed on this $68 \mathrm{E}$. coli isolates, for the detection of ESBL genes. Among them, 32.3\% of isolates harbor the ESBL genes. The multiplex PCR was discriminatory to genes encoding SHV, TEM, CTXm and OXA. The CTX-M gene was detected in $72.7 \%$ of the isolates, followed by TEM (54.5\%), OXA (36.3\%) and SHV (31.8\%). Followed by 68 isolates of E. coli were tested for biofilm production by the tube adherence method.

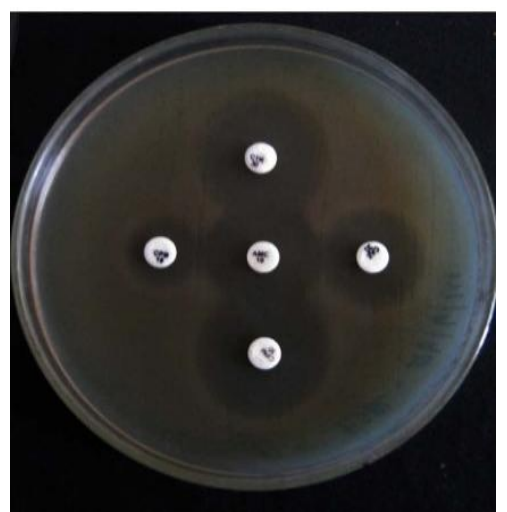

Fig. 1: Determination of ESBL by double disc synergy method.

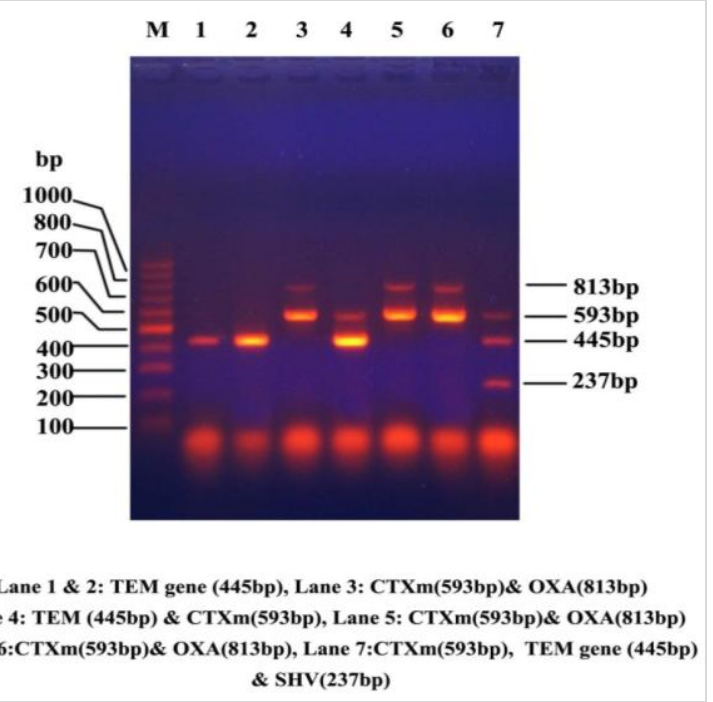

Fig. 2: Amplification of ESBL genes by Multiplex PCR.

Out of 125 diarrheal stools analyzed, 68 samples containing the E. coli isolates. It revealed $54.4 \%$ occurrence rate of $E$. coli in diarrheal stool samples. Among them, $53 \%$ of isolates were biofilm producers. The double disk diffusion method showed the presence of 22 ESBL producing isolates representing 32.3\%. In this study single isolate had 4 types of ESBL genes and followed by 3isolates had 3 ESBL genes (Figs. 2 and 3). It was found that biofilm producing isolates mostly harbored the ESBL genes in comparison with nonbiofilm producers (Table 2).

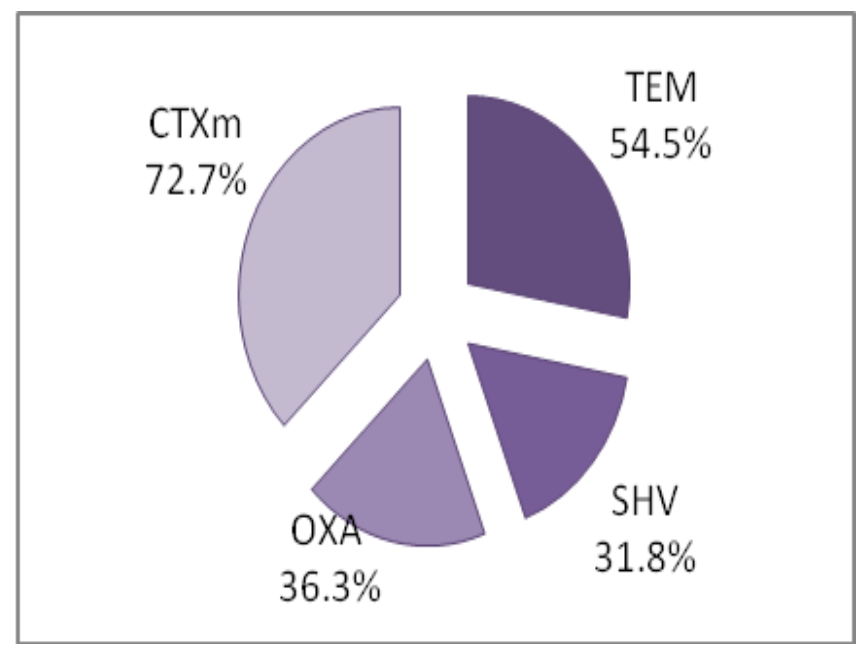

Fig. 3: Percentage of ESBL genes in E. coli isolates.

Many bacteria can produce the biofilm, the population of cells growing on the surface and enclosed in an exopolysaccharide matrix. Biofilm producing isolates was very difficult to eradicate, because of its higher antibiotic resistance. In our current study, 53\% of the isolates have shown the potential to make biofilms in comparison to previous studies, which report to $54 \%$ (Hasan et al., 2011).

Over the years, resistance to beta lactams among the members of $E$. coli has increased mainly due to the spreading of ESBL. In India, there have been several reports on the prevalence of ESBL in recent years (Hemachandran et al., 2012; Sankar et al., 2012; Subramanian et al., 2012; George et al., 2014). The prevalence of ESBL producing E. coli isolates evaluated in the present study was $32.3 \%$ in comparison to a similar study of George et al., 2014, which report showed 33\%.In this study ESBL was determinate by phenotypic and genotypic method; similar results were observed from both methods. But same time, using PCR amplification of resistance genes seems to have $100 \%$ specificity and sensitivity (Yazdi et al., 2012). In our study phenotypically confirmed isolates had at least one of the ESBLs genes. Our results were contrary to previous study of Veena et al. (2013). They people justified the difference between the phenotypic and genotypic. 
Table 2. Determination of biofilm and nonbiofilm producing ESBL genes.

\begin{tabular}{lllll}
\hline Biofilm formation & TEM & CTXM & OXA & SHV \\
\hline Biofilm positive & $30.5 \%$ & $44.4 \%$ & $13.8 \%$ & $16.6 \%$ \\
Non biofilm & $3.2 \%$ & $0 \%$ & $9.3 \%$ & $3.2 \%$ \\
\hline
\end{tabular}

The ESBL isolates usually carry the multiple resistance genes. In this study 7 isolates were harboring the blaTEM + CTXm and 4 isolates harbour blaSHV + CTXm and CTXm + OXA. Similar results have been observed by Veena et al. (2013) and Yazdi et al. (2012). In this present investigation, CTXm $(72.7 \%)$ was most abundant in the samples and followed by TEM (54.5\%). The CTXm enzyme is the predominant type of ESBL found in many regions of the world including Asian countries. In a study conducted from India by Roy (2011) report blaCTX-M was the most common genotype isolated. In this study, we observed that ESBL producing $E$. coli had higher ability to form biofilm in comparison with non biofilm ESBL isolates. Our study was related to a previous study of Subramanian et al. (2012). Biofilm protects the bacterium from host defense mechanisms and antibiotic action. Prevent the biofilm formation may enhance the ability of existing antibiotics to clear infections involving biofilm.

In conclusion, the present study shows high rate of faecal carriage of biofilm and ESBL producing E. coli in patients. Most of the isolates harboured atleast one or two ESBL genes and the most common genotype being the CTX-M. Our study indicates the biofilm producers are mostly harbored the ESBL genes in comparison with non biofilm producers. The importance of continued surveillance and monitoring of antibiotic resistance, which was overcome the ESBL producing infections.

\section{Conflict of interest statement}

Authors declare that they have no conflict of interest.

\section{References}

Christensen, G.D., Simpson, W.A., Bismo, A.L., Beachery, E.H., 1982. The adherence of the slime-producing strains of Staphylococcus epidermidis to smooth surfaces. Infect. Immun. 37, 318-326.

Costerton, J.W., Stewart, P.S., Greenberg, E.P., 1999. Bacterial biofilms: A common cause of persistent infections. Science. 284(5418), 1318-1322.

Cowan, S.J., Steel, K.J., 1974. Cowan and Steel Manual for Identification of Medical Bacteria. $2^{\text {nd }}$ Edn. Cambridge University Press, London. pp.176-232.

Fang, H., Ataker, F., Hedin, G., Dornbusch, K., 2008. Molecular epidemiology of extended-spectrum beta lactamases among Escherichia coli isolates collected in a Swedish hospital and its associated health care facilities. J. Clin. Microbiol. 46(2), 707-712.

Ferro, T. A. F., Moraes, F. C., da Silva, A. M., Porcy, C., Soares, L. A., Monteiro, C. A., Melo Lobao, N.T., Assis de Mello, F. A., Monteiro-Neto, V., de Maria Silva Figueirêdo, P., 2012. Characterization of virulence factors in Enteroaggregative and atypical enteropathogenic Escherichia coli strains isolated from children with diarrhea. Adv. Inf. Dis. 2(4), 1-8.

George, E.A., Sankar, S., Jesudasan, M.V., Sudandiradoss, C., Nandagopal, B., 2014. Incidence of extended spectrum beta lactamase producing Escherichia coli among patients, healthy individuals and in the environment. Ind. J. Med. Microbiol. 32(2), 172-174.

Hassan, A., Usman, J., Kaleem, F., Omair, M., Khalid, A., Iqbal, M., 2011. Detection and antibiotic susceptibility pattern of biofilm producing Gram positive and Gram negative bacteria isolated from a tertiary care hospital of Pakistan. Malays. J. Microbiol. 7, 57-60.

Hemachandran, K., Bharathi, S., Radhakrishnan, M., 2011. Studies on extended beta lactamase producing, biofilm forming clinical bacterial pathogens and its in vitro inhibition by Actinobacterial extracts. J. Appl. Pharmaceut. Sci. 1(8), 210-213.

Kaur, J., Chopra, S., Sheevani, M. G., 2013. Modified double disc synergy test to detect ESBL production in urinary isolates of Escherichia coli and Klebsiella pneumoniae. J. Clin. Diagn. Res. 7(2), 229-233.

Murugan, S., Uma Devi, P., Neetu John, P., 2011. Antimicrobial susceptibility pattern of biofilm producing Escherichia coli of urinary tract infections. Curr. Res. Bacteriol. 4, 73-80.

Ponnusamy, P., Nagappan, R., 2013. Extended spectrum betalactamase, biofilm-producing uropathogenic pathogens and their antibiotic susceptibility patterns from urinary tract infection- An overview. Int. J. Microbiol. Res. 4(2), 101-118.

Pourakbari, B., Ferdosian, F., Mahmoudi, S., Teymuri, M., Sabouni, F., Heydari, Ashtiani, M. T. H., Mamishi, S., 2012. Increase resistant rates and ESBL production between $E$. coli isolates causing urinary tract infection in young patients from Iran. Braz. J. Microbiol. 43(2), 766769.

Roy, S., Mukherjee, S., Singh, A.K., Basu, S., 2011. CTX-M-9 group extended-spectrum $\beta$-lactamases in neonatal stool isolates: Emergence in India. Ind. J. Med. Micrbiol. 29, 305-308.

Sankar, S., Narayanan, H., Kuppanan, S., Nandagopal, B., 2012. Frequency of extended-spectrum $\beta$-lactamase producing Gram-negative bacilli in a 200-bed multispecialty hospital in Vellore district, Tamil Nadu, India. 
Infection. 40, 425-429.

Singhai, S., Mathur, T., Khan, S., Upadhyay, D.J., Chugh, S., Gaind, R., 2005. Evaluation of methods for AmpC betalactamase in gram negative clinical isolates from tertiary care hospitals. Ind. J. Med. Microbiol. 23, 120-124.

Subramanian, P., Umadevi, S., Kumar, S., Stephen, S., 2012. Determination of correlation between biofilm and extended spectrum $\beta$ lactamases producers of Enterobacteriaceae. Schol. Res. J. 2, 2-6.

Veena, K., Vijaykumar, G.S., Sudeepa Kumar, M., Prashanth,
H.V., Prakash, R., Nagaraj, E.R., 2013. Phenotypic and genotypic methods for detection of extended spectrum $\beta$ lactamase producing Escherichia coli and Klebsiella pneumoniae isolated from ventilator associated pneumonia. J. Clin. Diagn. Res. 7(9), 1975-1978.

Yazdi, M., Nazemi, A., Mirinargasi, M., Jafarpour, M., Sharifi, S. H., 2012. Genotyping versus phenotyping methods to detect extended-spectrum beta-lactamase (ESBLs) in uropathogenic Escherichia coli. Ann. Biol. Res. 3(5), 2454-2458.

\section{How to cite this article:}

Jegadeeshkumar, D., Rajen, K. S., Nirmala, P., Gopinath, L. R., Prakash, B., 2016. Determination of acquaintance between biofilm and extended spectrum B-lactamases producers from diarrheal stool isolates of Escherichia coli. Int. J. Curr. Res. Biosci. Plant Biol. 3(10), 174-178.

doi: http://dx.doi.org/10.20546/ijcrbp.2016.310.022 